\title{
BM] Global Health Cost-effectiveness of club-foot treatment in low-income and middle-income countries by the Ponseti method
}

\author{
Caris E Grimes, ${ }^{1}$ Hampus Holmer, ${ }^{2}$ Jane Maraka, ${ }^{3}$ Birhanu Ayana, ${ }^{4}$ \\ Linda Hansen, ${ }^{5}$ Christopher B D Lavy ${ }^{6}$
}

To cite: Grimes $\mathrm{CE}$,

Holmer H, Maraka J, et al. Cost-effectiveness of clubfoot treatment in low-income and middle-income countries by the Ponseti method. BMJ Global Health 2016;1: e000023. doi:10.1136/ bmjgh-2015-000023

Received 14 December 2015 Revised 3 February 2016 Accepted 26 February 2016
CrossMark

For numbered affiliations see end of article.

\section{Correspondence to}

Dr Caris E Grimes:

carisgrimes@doctors.org.uk

\section{ABSTRACT}

Background: Club foot is a common congenital deformity affecting 150 000-200 000 children every year. Untreated patients end up walking on the side or back of the affected foot, with severe social and economic consequences. Club foot is highly treatable by the Ponseti method, a non-invasive technique that has been described as highly suitable for use in resource-limited settings. To date, there has been no evaluation of its cost-effectiveness ratio, defined as the cost of averting one disability-adjusted life year (DALY) a composite measure of the impact of premature death and disability. In this study, we aimed to calculate the average cost-effectiveness ratio of the Ponseti method for correcting club foot in sub-Saharan Africa.

Methods: Using data from 12 sub-Saharan African countries provided by the international non-profit organisation CURE Clubfoot, which implements several Ponseti treatment programmes around the world, we estimated the average cost of the point-of-care treatment for club foot in these countries. We divided the cost of treatment with the average number of DALYs that can be averted by the Ponseti treatment, assuming treatment is successful in $90 \%$ of patients. Results: We found the average cost of the Ponseti treatment to be US\$167 per patient. The average number of DALYs averted was 7.42, yielding a costeffectiveness ratio of US\$22.46 per DALY averted. To test the robustness of our calculation different variables were used and these yielded a cost range of US\$5.28-29.75. This is less than a tenth of the cost of many other treatment modalities used in resource-poor settings today.

Conclusions: The Ponseti method for the treatment of club foot is cost-effective and practical in a low-income country setting. These findings could be used to raise the priority for implementing Ponseti treatment in areas where patients are still lacking access to the life-changing intervention.

\section{INTRODUCTION}

Club foot or congenital talipes equinovarus (CTEV) is one of the most common congenital musculoskeletal deformities, and occurs approximately in one in 800 live births. ${ }^{1-3}$ The vast majority of patients are found in

\section{Key questions}

What is already known about this topic?

- Club foot is a common congenital deformity resulting in significant social and economic consequences.

- Club foot is treatable without an anaesthetic by using the Ponseti method involving serial manipulation and plaster casting.

- The Ponseti method is clinically effective in treating disability due to club foot.

- The Ponseti method is suitable for low resource settings as it does not require a trained surgeon or an anaesthetist.

What are the new findings?

- The average treatment cost using the Ponseti method is US\$167.

- The cost-effectiveness ratio is US\$22.46 per disability-adjusted life year averted.

- This is highly cost-effective compared with many other global health conditions.

\section{Recommendations for policy}

- Ministries of Health should consider putting club-foot treatment into national health plans.

- Simple non-operative treatment stops disability and gives children a chance of education and employment.

low-income and middle-income countries (LMICs). Untreated CTEV can lead to severe deformity, but with timely and correct management it is curable.

CTEV is defined as an inward rotation of the foot, with four components: cavus, forefoot adductus, hind foot varus and equinus. Two of three patients occur in boys and in every other case, the condition affects both feet. ${ }^{1-3}$ The deformity causes patients to walk on the side or back of their feet leading to callus formation, and potential infections in the skin and bone. With severely hampered mobility, these patients are unable to work; thus, this deformity contributes not only to ill health but also to poverty. ${ }^{4-6}$ 
Several techniques are available to correct CTEV, and often involve invasive surgery. ${ }^{7}$ Since 1996 , however, the non-surgical Ponseti method of correction has become increasingly popular, ${ }^{8}$ proving to be effective in more than $90 \%$ of patients. ${ }^{9} 10$ The technique encompasses gradual manipulation of the foot into the correct position through the aid of serial application of casts, generally followed by a percutaneous tenotomy of the Achilles tendon and a prolonged follow-up programme with foot abduction braces. ${ }^{11}$ Initially reserved for early correction of uncomplicated idiopathic patients, today the Ponseti method is being adapted for complex non-idiopathic patients and for patients presenting up to and beyond 2 years of age. ${ }^{4} 1213$

Widely implemented in high-income countries, the Ponseti method has been described as highly suitable for healthcare settings with scarce resources and is being increasingly used in LMICs as well. ${ }^{8} 14$ Today, programmes for training and implementation of CTEV treatment by using the Ponseti method are being implemented in most countries in the world, often with considerable success. ${ }^{5}{ }^{815-19}$ A recent study by Shabtai and colleagues found evidence of the Ponseti treatment being offered in 113 of the 193 United Nations member states. However, 80 countries have no evidence of such activity, and in most countries the programmes do not cover all new patients. ${ }^{19}$ Many programmes are initiated or supported by international Non-governmental Organisations (NGOs) such as Ponseti International ${ }^{20}$ and CURE Clubfoot. ${ }^{21}$

In spite of increasing political priority for addressing disabilities $^{22}$ and a growing body of evidence establishing the Ponseti method as a feasible, effective and low-cost intervention, to the best of our knowledge, there are no published studies quantifying the cost-effectiveness of the method. The cost-effectiveness ratio, that is, the cost of averting one disability-adjusted life year (DALY), has been applied to over 300 treatment modalities for a range of conditions. ${ }^{2324}$ The DALY is a measure used to calculate the number of years lost due to disability, illhealth or premature death. ${ }^{25}$ By calculating the cost of averting lyear lost to disability due to CTEV, the costeffectiveness of the Ponseti treatment can be compared to other conditions for which the same calculation has been carried out.

To fill in this knowledge gap, and to facilitate comparisons with other disease categories and treatment modalities, we aimed to calculate the cost of Ponseti treatment per DALY averted in the African continent using published data and cost estimates from the CURE Clubfoot programme in 12 countries in sub-Saharan Africa.

\section{METHODS}

To calculate the cost-effectiveness ratio of the Ponseti method for correction of CTEV, we first calculated the average cost of treatment and the average number of DALYs averted with treatment, and then derived a ratio between these two variables. We calculated separate costeffectiveness ratios for unilateral and bilateral CTEV, as well as the average between the two. The latter gives a number that more closely resembles the actual situation in CTEV programmes where unilateral and bilateral patients are treated, with roughly equal frequency. This study adheres to the Consolidated Health Economic Evaluation Reporting Standards. ${ }^{26}$

\section{Cost of treatment}

To calculate the average cost of treatment (in United States dollars, US\$), we obtained data from the African regional office of CURE Clubfoot, an international NGO, on the average cost of treatment per patient for unilateral and bilateral CTEV within their programmes in Africa. The costs of staff and supplies were included, but cost of training, hospital infrastructure, administration and outreach, and communication activities were excluded as this varies significantly between countries. The costs of unilateral and bilateral CTEV were calculated separately, and an average of the two was calculated.

CURE is a Christian non-profit organisation that was founded in $1986^{27}$ and has on-going Ponseti treatment programmes in 16 countries, of which 12 are situated in sub-Saharan Africa (Burundi, DR Congo, Ethiopia, Ghana, Kenya, Malawi, Niger, Rwanda, Mozambique, Togo, Zambia and Zimbabwe). ${ }^{21}$

\section{Quantifying disability caused by CTEV}

To quantify the disability caused by CTEV, we calculated the number of DALYs attributable to CTEV. The DALY, extensively described elsewhere, ${ }^{25} 28$ is a composite measure of the number of years lost due to premature death and the number of years lost due to disability. Since CTEV does not directly lead to premature death, we focused exclusively on the latter.

The number of years lost due to disability is calculated using the so-called disability weight, a number between zero and one assigned to a number of conditions as part of the Global Burden of Disease study. Since the Global Burden of Disease study has yet to define a specific disability weight for CTEV, we used a disability weight of 0.231 for unilateral CTEV. This is the same as for untreated cleft palate, ${ }^{29}$ and has been used previously as a surrogate for $\mathrm{CTEV}^{30}$ In the case of bilateral CTEV, however, we used the disability weight assigned to disability due to poliomyelitis as a surrogate, $0.369 .^{29}$

Finally, the disability weight is multiplied by the number of years lived with a condition to establish the number of healthy years lost to disability. In the case of CTEV - a life-long condition if left untreated-this corresponds to the full life expectancy of the studied population. In this case, we used the most recent available (2013) average life expectancy at birth in the WHO African Region. ${ }^{31}$ Accounting for the 2:1 male to female ratio among patients of CTEV, the average life expectancy in the infant patient population is 58 years. 
Table 1 Average cost of the treatment of congenital talipes equinovarus using the Ponseti treatment method, based on CURE Clubfoot programmes in Africa

\begin{tabular}{|c|c|c|}
\hline & $\begin{array}{l}\text { Cost (US\$ per } \\
\text { patient) }\end{array}$ & Assumptions* \\
\hline \multicolumn{3}{|l|}{ Staff } \\
\hline Brace evaluation & 15 & $\begin{array}{l}20 \text { min per visit (same for unilateral and bilateral patients); } 14 \text { brace } \\
\text { reviews per patient; one health worker }{ }^{35} \dagger\end{array}$ \\
\hline Total staff cost, unilateral & 46 & \\
\hline Total staff cost, bilateral & 78 & Double costs for casting and tenotomy \\
\hline \multicolumn{3}{|l|}{ Supplies } \\
\hline Casting, unilateral & 25 & $\begin{array}{l}\text { Two rolls of cast and under-cast padding per leg, at US } \$ 3.50 \text { total; } \\
\text { seven castings }\end{array}$ \\
\hline Total cost of supplies, unilateral & 72 & \\
\hline Total cost of supplies, bilateral & 90 & Double costs for casting and tenotomy \\
\hline Total cost, unilateral & 136 & \\
\hline Total cost, bilateral & 197 & \\
\hline Average total cost & 167 & \\
\hline
\end{tabular}

*Data from CURE Clubfoot.

†Health worker salary estimated at US $\$ 500$ per month, with a 40 hour working week, equal to roughly US $\$ 3$ per hour.

These data were entered into a modified version of the WHO DALY calculation template. ${ }^{32}$ Following the WHO guidelines on cost-effectiveness analysis, we used $3 \%$ discounting, ${ }^{33}$ a factor that decreases the calculated value of future DALYs in an effort to balance the pursuit of future benefits with that of addressing more immediate needs. ${ }^{33}$ We took into consideration the fact that some $10 \%$ of treatments may not be successful in providing a permanent cure ${ }^{9}{ }^{10}$ by adding a factor 0.9 to the final calculation. Separate DALY calculations were carried out for unilateral and bilateral CTEV, and an average of the two was derived.

\section{Cost-effectiveness ratio}

We calculated the cost-effectiveness ratio by dividing the calculated cost of treatment with the Ponseti method by the number of DALYs averted for unilateral and bilateral CTEV, respectively, and also calculated an average of the two.

We performed a sensitivity analysis by replacing our cost estimate with a previously published estimate of the cost of treatment with the Ponseti method in Pakistan; ${ }^{34}$ using the same disability weight across unilateral and bilateral CTEV; and eliminating the discounting and introducing age weighting, a factor that gives a higher value to years lived as an adult than childhood, as proposed in the WHO guidelines on cost-effectiveness analysis. ${ }^{33}$ The range from minimum to maximum cost-effectiveness ratios derived from sensitivity analysis was tabulated along with the average cost-effectiveness ratio.

\section{Patient involvement}

No patients were involved in the concept, design or outcome methods from this study.

\section{RESULTS}

The average cost of the full Ponseti treatment was US $\$ 140$ per patient-an average for patients with unilateral and bilateral CTEV in the CURE Clubfoot programmes in 12 countries in sub-Saharan Africa (table 1).

On average, treating CTEV averts 7.42 DALYs (table 2). This corresponds to an average cost-effectiveness ratio of US\$22.46 per DALY averted for the Ponseti method of

Table 2 Average number of avertable DALYs per patient

\begin{tabular}{llllll}
\hline & Duration $^{*}$ & Discount rate & Success rate & Disability weight & $\begin{array}{l}\text { Average avertable } \\
\text { DALYs per patient }\end{array}$ \\
\hline Unilateral & 58 years $^{31}$ & $3 \%$ & $90 \%{ }^{9}{ }^{10}$ & $0.231^{2930}$ & 5.71 \\
Bilateral & & & & $0.369^{29}$ & 9.13 \\
Average & & & & & 7.42 \\
\hline
\end{tabular}

${ }^{*}$ Corresponds to life expectancy among infants with congenital talipes equinovarus (2:1 male to female ratio). 
Table 3 Cost-effectiveness ratio comparison

\section{Cost per DALY}

averted (US\$)

\begin{tabular}{ll}
\hline $\begin{array}{l}\text { Ponseti treatment for congenital } \\
\text { talipes equinovarus (average, Africa) }\end{array}$ & $18.92(7.45-29.75)^{\star}$ \\
\hline Opthalmic surgery & $5.06-285^{36}$ \\
\hline Adult male circumcision for HIV & $7.38-319^{36}$ \\
\hline Hernia repair & $10.98-172^{36}$ \\
\hline Caesarean section & $304^{36}$ \\
\hline
\end{tabular}

*Minimum and maximum values derived from sensitivity analysis.

treating CTEV. This compares favourably to interventions for other conditions (table 3).

In our sensitivity analysis, we found the costeffectiveness ratio to decrease to below US\$6 per DALY averted, without discounting and using age weighting. Using a previously published cost of US $\$ 170$ per treatment, and applying the same disability weight of 0.231 to bilateral and unilateral CTEV yielded a maximum cost of US\$30 per DALY averted.

\section{DISCUSSION}

In this study, we found the Ponseti method for the treatment of CTEV in sub-Saharan Africa to be highly costeffective, comparing very favourably with other interventions that are commonly used in LMICs. ${ }^{23}$ This result adds to a growing body of evidence, suggesting that Ponseti treatment would be highly suitable for implementation in all countries. Previous studies have highlighted the safety and efficacy of the method, even in patients of delayed presentation or complex deformity. ${ }^{4} 1213$ The technique can easily and successfully be taught to various levels of healthcare professionals, with success rates similar to those in high-income countries. ${ }^{16}{ }^{37}$ By avoiding the use of surgery (except for a small, percutaneous incision under local or no anaesthesia), CTEV treatment with the Ponseti method can be decentralised to rural areas, thus increasing access to services and reducing the costs. This takes a large burden off the few doctors and surgeons in countries, ${ }^{38}{ }^{39}$ and saves patients from an otherwise severely debilitating deformity. This has far ranging consequences in terms of individual well-being and socioeconomic participation in society.

Not only is the Ponseti method for correction of CTEV cost-effective and suitable for implementation in any setting, it has also been implemented very successfully in a number of low-income countries. Programmes like those run by CURE Clubfoot or the Uganda Sustainable Clubfoot Care Project engage ministries of health and include the development of a national strategic plan, raising of community awareness and training of local healthcare personnel. Locally-made braces and other equipment are often used and locally adapted solutions are developed to address barriers to adherence to the treatment programme; this ensures sustainability and continuous quality improvement. ${ }^{5} 1422$ Yet, a recent study suggested that there is still low or no coverage of the intervention in large parts of the world. ${ }^{19}$

From what we know, this study provides the first published cost-effectiveness ratio, but it has some limitations. We sought to test the robustness of our findings by doing a sensitivity analysis, but some key limitations merit further elaboration here.

First, calculations on the cost of treatment are based on a number of assumptions that are outlined in the Methods section and in table 1 . Costs may vary considerably across different settings (previously published figures ranging from US $\$ 170$ in Pakistan ${ }^{34}$ to over US $\$ 30000$ for Ponseti treatment of recurring bilateral CTEV in the $\mathrm{USA}^{39}$ ), and depend on which expenses are included in the calculation. We included only cost at the point of care, excluding training and mentoring, infrastructure, outreach, patient education and administration, in order to facilitate comparison with other treatment modalities where such costs were also excluded. ${ }^{23}$ In reality, however, investment in the healthcare system plays a central role for the success of Ponseti treatment programmes as services are delivered within the existing healthcare system. ${ }^{5}$ The study by Hussain et $a l^{34}$ from Pakistan showed that indirect costs to the patient can be significant even when treatment is free. This constitutes one important barrier to accessing care; however, other barriers also exist such as poor transport and lack of awareness. ${ }^{40}$ Local data collection will help to further elucidate the costs in different settings as well as specific barriers and possible solutions.

Second, although the DALY is an established and commonly used metric for measuring death and disability incurred by specific conditions, it is an imperfect measure with its own intrinsic limitations. ${ }^{25}$ Since CTEV lacks a specific disability weight used for calculating the DALYs attributable to the condition, we had to use surrogate numbers (one for unilateral and another for bilateral CTEV), that were equal to those for conditions that we found to most closely resemble the level of disability caused by CTEV. Although arbitrary, this selection process is in line with the original methodology of the DALY. ${ }^{9} 9$

Finally, it should be acknowledged that although implementing Ponseti treatment programmes in developing countries is highly cost-effective, it does raise some issues and most of these are not by any means unique to the Ponseti method. Ensuring access to treatment is one particularly difficult issue; others relate to securing funding and materials, recruiting and training staff, and inability of patients to attend follow-up visits. The alternative treatment modality, surgical correction, fares far worse in comparison.

\section{CONCLUSION}

We found the Ponseti method for the treatment of CTEV to be cost-effective in a low-income country setting. Our findings should be used to raise the priority 
for implementing Ponseti treatment in areas where patients are still lacking access to the life-changing intervention, with the goal to ensure that all children born with CTEV are able to live a full life, free of a preventable disability.

\author{
Author affiliations \\ ${ }^{1}$ Kings Centre for Global Health and Kings Health Partners, Kings College \\ London, London, UK \\ ${ }^{2}$ Department of Clinical Sciences, Paediatric Surgery and Global Paediatrics, \\ Faculty of Medicine, Lund University, Lund, Sweden \\ ${ }^{3}$ East of England Deanary, Cambridge, UK \\ ${ }^{4}$ Black Lion Hospital, Addis Ababa, Ethiopia \\ ${ }^{5}$ Beit CURE Hospital, Lusaka, Zambia \\ ${ }^{6}$ Nuffield Department of Orthopaedics, Rheumatology and Musculoskeletal \\ Sciences, University of Oxford, Oxford, UK
}

Handling editor Seye Abimbola

CHEERS Statement This study adheres to the Consolidated Health Economic Evaluation Reporting Standards (CHEERS).

Contributors CEG, CBDL and JM conceived and designed the study. CBDL, $\mathrm{HH}$ and $\mathrm{LH}$ carried out data collection. CEG and HH analysed the data, and wrote the first draft of the manuscript. BA assisted with revising the draft of the paper into its final form. All authors contributed to the final version of the manuscript.

Funding CEG was supported by the Sir Ratanji Dalal Scholarship from the Royal College of Surgeons of England. HH received a travel grant from Lund University, Sweden.

Competing interests None declared.

Provenance and peer review Not commissioned; externally peer reviewed.

Data sharing statement No additional data are available.

Open Access This is an Open Access article distributed in accordance with the Creative Commons Attribution Non Commercial (CC BY-NC 4.0) license, which permits others to distribute, remix, adapt, build upon this work noncommercially, and license their derivative works on different terms, provided the original work is properly cited and the use is non-commercial. See: http:// creativecommons.org/licenses/by-nc/4.0/

\section{REFERENCES}

1. Parker SE, Mai CT, Strickland MJ, et al. Multistate study of the epidemiology of clubfoot. Birth Defects Res Part A Clin Mol Teratol 2009;85:897-904

2. Wynne-Davies R. Family studies and the cause of congenital club foot. Talipes equinovarus, talipes calcaneo-valgus and metatarsus varus. J Bone Joint Surg Br 1964;46:445-63.

3. Mathias RG, Lule JK, Waiswa G, et al. Incidence of clubfoot in Uganda. Can J Public Health 2010;101:341-4.

4. Dobbs MB, Gurnett CA. Update on clubfoot: etiology and treatment. Clin Orthop Relat Res 2009:467:1146-53.

5. Pirani S, Naddumba E, Mathias R, et al. Towards effective Ponseti clubfoot care: the Uganda Sustainable Clubfoot Care Project. Clin Orthop Relat Res 2009;467:1154-63.

6. Radler $\mathrm{C}$. The Ponseti method for the treatment of congenital Club foot: review of the current literature and treatment recommendations. Int Orthop 2013;37:1747-53.

7. Dobbs MB, Morcuende JA, Gurnett CA, et al. Treatment of idiopathic clubfoot: an historical review. lowa Orthop J 2000;20:59-64.

8. Penny JN. The neglected clubfoot. Tech Orthop 2005;20:153-66.

9. Cooper DM, Dietz FR. Treatment of idiopathic clubfoot. A thirty-year follow-up note. J Bone Joint Surg Am 1995;77:1477-89.

10. Herzenberg JE, Radler C, Bor N. Ponseti versus traditional methods of casting for idiopathic clubfoot. J Pediatr Orthop 2002;22:517-21.

11. Ponseti IV. Congenital clubfoot: fundamentals for treatment. Oxford: Oxford University Press, 1996.

12. Lourenco AF, Morcuende JA. Correction of neglected idiopathic club foot by the Ponseti method. J Bone Joint Surg Br 2007;89:378-81.
13. Spiegel DA, Shrestha OP, Sitoula $P$, et al. Ponseti method for untreated idiopathic clubfeet in Nepalese patients from 1 to 6 years of age. Clin Orthop Relat Res 2009;467:1164-70.

14. Debas HT, Donkor P, Gawande A, et al. Disease control priorities, third edition: volume 1. Essential surgery. Washington (DC): World Bank, 2015.

15. Owen RM, Penny JN, Mayo A, et al. A collaborative public health approach to clubfoot intervention in 10 low-income and middle-income countries: 2-year outcomes and lessons learnt. $J$ Pediatr Orthop B 2012;21:361-5.

16. Lavy CB, Mannion SJ, Mkandawire NC, et al. Club foot treatment in Malawi-a public health approach. Disabil Rehabil 2007;29:857-62.

17. Ford-Powell VA, Barker S, Khan MS, et al. The Bangladesh clubfoot project: the first 5000 feet. J Pediatr Orthop 2013;33:e40-4.

18. Evans AM, Van Thanh D. A review of the Ponseti method and development of an infant clubfoot program in Vietnam. J Am Podiatr Med Assoc 2009;99:306-16.

19. Shabtai L, Specht SC, Herzenberg JE. Worldwide spread of the Ponseti method for clubfoot. World J Orthop 2014;5:585-90.

20. Ponseti International. http://www.ponseti.info/index.html

21. CURE Clubfoot. https://cure.org/clubfoot/

22. World Health Organization. World report on disability. Geneva: WHO, 2011.

23. Laxminarayan R, Chow J, Shahid-Salles SA. Intervention cost-effectiveness: overview of main messages. In: Jamison DT, Breman JG, Measham AR, Alleyne G, Claeson M, Evans DB, Jha P Mills A, Musgrove P, eds. Disease control priorities in developing countries. 2nd Edition. Washington (DC): The International Bank for Reconstruction and Development/The World Bank Group, 2006, Chapter 2.

24. Priorities in Health. In: Jamison DT, Breman JG, Measham AR, Alleyne G, Claeson M, Evans DB, Jha P, Mills A, Musgrove P, eds. Washington DC: The International Bank for Reconstruction and Development/The World Bank Group, 2006.

25. Murray CJ, Acharya AK. Understanding DALYs (disability-adjusted life years). J Health Econ 1997;16:703-30.

26. Husereau D, Drummond M, Petrou S, et al. Consolidated Health Economic Evaluation Reporting Standards (CHEERS) statement. BMJ 2013;346:f1049.

27. CURE. About CURE. https://cure.org/about/

28. Murray CJ. Quantifying the burden of disease: the technical basis for disability-adjusted life years. Bull World Health Organ 1994;72:429-45.

29. Murray CJL, Lopez AD. The global burden of disease: a comprehensive assessment of mortality and disability from diseases, injuries, and risk factors in 1990 and projected to 2020. Cambridge (MA): Harvard School of Public Health, for the World Health Organization and the World Bank, 1996.

30. Gosselin RA, Gialamas G, Atkin DM. Comparing the cost-effectiveness of short orthopedic missions in elective and relief situations in developing countries. World J Surg 2011;35:951-5.

31. World Health Organization. Global health observatory data repository - life expectancy, data by WHO region: Africa. Geneva: WHO. http://apps.who.int/gho/data/view.main.690?lang=en

32. World Health Organization. Health statistics and information systems: National tools. Geneva: WHO. http://www.who.int/ healthinfo/global_burden_disease/tools_national/en/.

33. Edejer T, Baltussen R, Adam T, et al. WHO guide to cost-effectiveness analysis. Geneva: World Health Organisation, 2003.

34. Hussain H, Burfat AM, Samad L, et al. Cost-effectiveness of the Ponseti method for treatment of clubfoot in Pakistan. World J Surg 2014;38:2217-22.

35. McCoy D, Bennett S, Witter S, et al. Salaries and incomes of health workers in sub-Saharan Africa. Lancet 2008;371:675-81.

36. Grimes CE, Henry JA, Maraka J, et al. Cost-effectiveness of surgery in low- and middle-income countries: a systematic review. World J Surg 2014;38:252-63.

37. Tindall AJ, Steinlechner CW, Lavy CB, et al. Results of manipulation of idiopathic clubfoot deformity in Malawi by orthopaedic clinical officers using the Ponseti method: a realistic alternative for the developing world? J Pediatr Orthop 2005;25:627-9.

38. Holmer $\mathrm{H}$, Lantz A, Kunjumen $\mathrm{T}$, et al. Global distribution of surgeons, anaesthesiologists, and obstetricians. Lancet Glob Health 2015;3(Suppl 2):S9-11.

39. Halanski MA, Huang JC, Walsh SJ, et al. Resource utilization in clubfoot management. Clin Orthop Relat Res 2009;467:1171-9.

40. Grimes CE, Bowman KG, Dodgion CM, et al. Systematic review of barriers to surgical care in low-income and middle-income countries. World J Surg 2011;35:941-50. 


\section{Correction: Cost-effectiveness of clubfoot treatment in low and middle income countries by the Ponseti method}

Grimes CE, Holmer H, Maraka J, et al. Cost-effectiveness of club-foot treatment in low-income and middle-income countries by the Ponseti method. BMJ Glob Health 2016;1:e000023. doi: 10.1136/bmjgh-2015-000023

Author would like to highlight below important errors pertaining to tables and text: 1. Table 1 on page 3 , the total cost of supplies, unilateral should be 90 , and the total cost of supplies, bilateral should be 119 (please note that the sum total was not affected)

2. The first sentence in the results says that the average cost was 140 USD when it should be 167 USD (this is also the number cited in the table and abstract).

3 . The table on page four should read Ponseti treatment for congenital talipes equinovarus (average, Africa): 22.46 (5.28-29.75), not 18.92 (7.45-29.75)

Open access This is an Open access article distributed in accordance with the Creative Commons Attribution Non Commercial (CC BY-NC 4.0) license, which permits others to distribute, remix, adapt, build upon this work non-commercially, and license their derivative works on different terms, provided the original work is properly cited, appropriate credit is given, any changes made indicated, and the use is non-commercial. See: http://creativecommons.org/licenses/by-nc/4.0/.

(C) Author(s) (or their employer(s)) 2018. Re-use permitted under CC BY-NC. No commercial re-use. See rights and permissions. Published by BMJ.

BMJ Glob Health 2018;3:e000023corr1. doi:10.1136/bmjgh-2015-000023corr1 